\title{
THERMO-PNEUMATIC MICROPUMP FOR DRUG DELIVERY APPLICATIONS
}

\author{
N.A. Hamid ${ }^{*}$, B.Y. Majlis², J. Yunas² and M. Ibrahim ${ }^{3}$
}

\author{
${ }^{1}$ Fakulti Kejuruteraan Elektronik dan Kejuruteraan Komputer (FKEKK), \\ Universiti Teknikal Malaysia Melaka, 76100 Durian Tunggal, Melaka, Malaysia. \\ ${ }^{2}$ Institute of Microengineering and Nanoelectronics (IMEN), \\ Universiti Kebangsan Malaysia, 43600, Bangi, Selangor, Malaysia \\ ${ }^{3}$ Fakulti Teknologi Kejuruteraan (FTK), \\ Universiti Teknikal Malaysia Melaka, 76100 Durian Tunggal, Melaka, Malaysia.
}

*Corresponding Author's Email: norihan.hamid@utem.edu.my

Article History: Received December 18, 2021; Revised January 23, 2022;

Accepted January 25, 2022

\begin{abstract}
Micropumps constitute an essential part of precise delivery and directional volume control of fluid in a microfluidic system. In biomedical applications, micropump is widely used especially in drug delivery, biological fluid transmission, organic analysis, liquid measurement, and many more. In this paper, the concept and design structure hence fabrication of the Thermo pneumatic micropump prototype are explained. The experimental measurement of the micropump employing planar diffuser nozzle in transmits fluid is also presented. Thermopneumatic micropump is comprised of three different components which are the microheater on the bottom, the flexible thin membrane that acts as an actuator, and the planar diffuser nozzle on the top to channel the fluidic. These three components were fabricated separately due to the different materials and techniques used in each component. Finally, the whole micropump system was integrated using an anodic bonding technique. Bulk micromachining technique was used to fabricated the chamber and thin-film membrane, surface micromachining technique for the microheater while replica molding technique was used for the planar diffuser nozzle. The whole diameter size for the micropump was $25 \times 20 \times 1.6 \mathrm{~mm}$ respectively. The microscope image recorded video and data was used during the experimental measurement, to observed and calculate the flow rate of meniscus motion flow in the outlet tube of the micropump. At the end of the experiment, the flow rate range of the micropump measure was
\end{abstract}


approximately $770 \mathrm{pL}$ to $12.5 \mathrm{~nL}$, when the output of $2-12 \mathrm{Vdc}$ was applied to the microheater. This flow rate range is very suitable for drug delivery applications.

KEYWORDS: Thermo-pneumatic, micropump, drug delivery, thin-film membrane

\subsection{INTRODUCTION}

The emergence of MEMS microdevices has been pioneered in various fields over the decade. The new application of MEMS devices is being discovered continuously. Presently, MEMS technology and microdevice have embarked and been emphasized in the medical field including drug delivery and development, point of care diagnostic, sensitive bioanalytical systems, surgical and therapeutic microsystems. [1-3]. These microdevices have placed importance on the technology in providing a better outcome for the patient and a lower overall health care cost [4-5].

MEMS micropump has played a crucial role in controlling drug delivery to a specific target in these few years. Compare with the traditional oral and manual injection for therapeutic effect, consumption of micropump in drug delivery system is higher reliable and efficient [6-7]. Besides, micropumps offer precise dosage, continuously and automated delivery approach pharmaceutical therapy treatment [8-9]

This paper provides an explanation of thermo pneumatic micropump from the beginning of fabrication until the flowrate measurement for the completed micropump system. Three fabrication techniques have been described for the three-part of a micropump component such as bulk micromachining technique of microactuator membrane and chamber, surface micromachining technique for the microheater, and replica molding for the planar diffuser nozzle channel. Before that, the micropump's brief concept and structure were also presented. Next, the experimental setup for the flowrate measurement was explained in detail. At the end of the experiment, the measurement of flow rate is performed in a graph chart and a point of discussion is also provided. 


\subsection{CONCEPT AND STRUCTURE}

Thermo pneumatic micropump uses the concept thermal expansion method which involves the volume expansion or induces stress of material in response to change in temperature or heat convection as can be seen in Figure 1. Based on thermally induced volume change or phase change of fluid that occurred in a chamber, periodically change in volume of chamber results a pressure change inside the cavity to actuate membrane. Liquid pressure change can be expressed as:

$$
\Delta P=E\left(\beta \Delta T-\frac{\Delta V}{V}\right)
$$

where $\Delta P$ is a pressure change, $E$ the bulk modulus of elastic, $\beta$ the volume coefficient thermal expansion, $\Delta T$ the temperature increase and $\frac{\Delta V}{V}$ is the volume change percentage body [10].

In summary, membrane deflection is directly proportional to the change of temperature inside the chamber. This is also due to the elastic material properties of the membrane which can be expanded when heated. Therefore, when the microheater heats up, air space inside the microchamber will expand. At this point, volume expansion will cause the membrane to deflect and fluid was sucked into to pump. The fluid will pump out from the chamber when the heaters are cooling down.

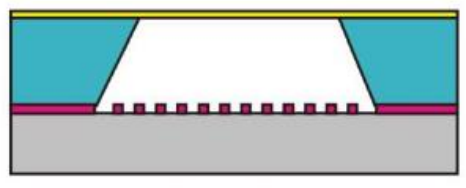

$\Delta T=0$

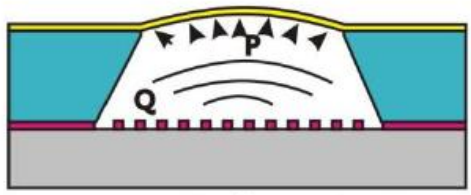

$\Delta T>0 \Rightarrow \Delta P>0$

Figure 1: Concept of thermal expansion that produces pressure on the thin-film membrane when heated by the microheater.

\subsection{Thermo pneumatic micropump structure}

Thermo pneumatic micropump was constructed from microheaterater as the air supply for the pump thin-film membrane act as an actuator complete with microchamber heater as well as microchannel for fluid flow. The microheater was the main supply for the Thermo pneumatic micropump. The thin-film membrane was acted as an actuator to attract and push the fluid into the chamber while the fluid chamber is the component used during the fluid pumping process. The trapped volume air in the microchamber will be heated when the microheater 
receivers the power supply hence planar diffuser nozzle was channeling the fluid flow or to control the fluid movement.

Figure 2. represents a side view of the micropump consisting of three layers of the substrate structure. The first layer is the substrate for the microheater, followed by a thin film membrane with a heating chamber on the second layer and the final layer of the planar diffuser nozzle element. The overall dimension of the pump is approximately $25 \times 20$ $x 1.6 \mathrm{~mm}$. A three-dimensional image of the micropump is depicted in Figure 3. Each pump component is fabricated separately due to the different processes and materials used. After the functionality and measurement testing for each component is completed, all components are combined using anodic bonding.

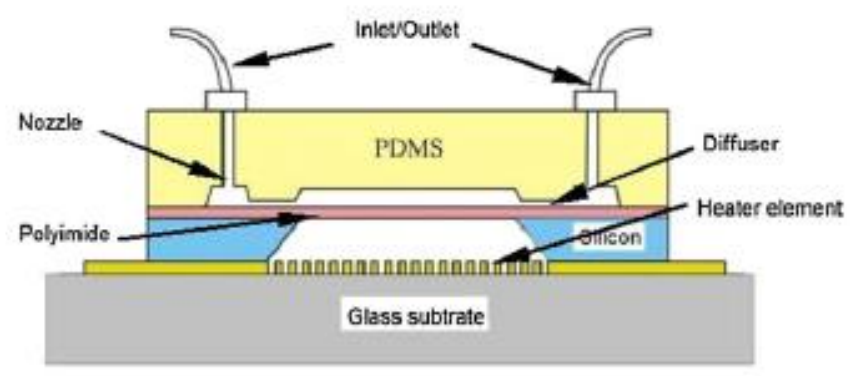

Figure 2: Side view of Thermo pneumatic micropump

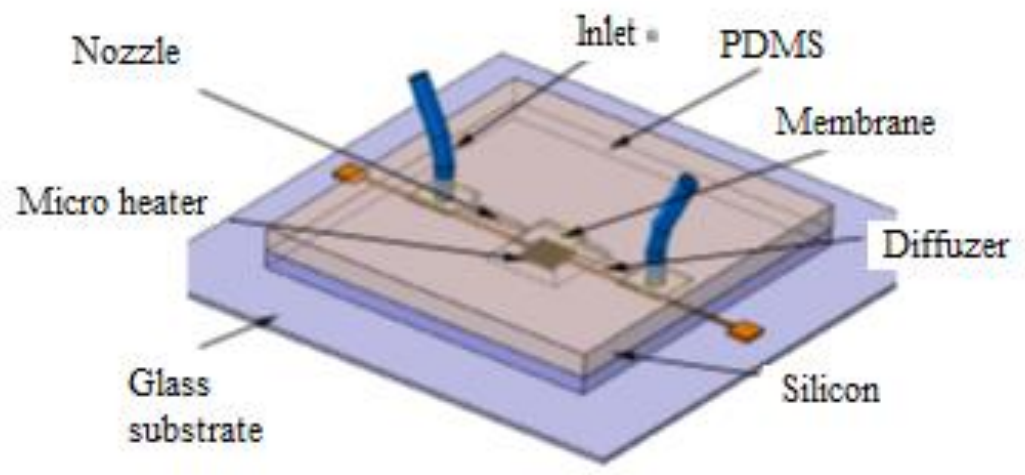

Figure 3: 3-dimensional view Thermo pneumatic micropump

Micro heater structure consists of thin-film metal elements that are deposited on a silica boron glass substrate. Besides good thermal insulation, silica boron glass is also transparent thus having the advantage to facilitate the process of aligning the entire component at 
the end of the fabrication process later. The micro heating element can generate thermal energy to expand the air volume in the heating chamber and turn to deflect the thin film membrane that acts as a microactuator on the Thermo pneumatic micropump system. When this condition occurs, the pressure difference between the inlet, chamber, and outlet will allow fluid to flow in and out of the pump [11,12].

The heating chamber and flow chamber structure are designed separately to prevent the contamination of the fluid that is pumped in and out of the micropump. Normally, when heating occurs heater is concerned to produce dust or particles that can change the structure of fluid therefore by separating the design, contamination can be avoided. Thermo pneumatic micropump also choose planar diffuser nozzle because of the capability to produce a high flow rate $[13,14]$ reduce clogging $[15,16]$ with low cost and ease fabrication process $[17,18]$

\subsection{DEVICE FABRICATION}

Thermo pneumatic micropump are separated into three different components which are micro heater fabrication, the diaphragm of the thin-film membrane with heater chamber fabrication, and planar diffuser nozzle fabrication. Each of these components has an essential function in the micropump system. The micropump involve three separation process due to different material and technique used. Micro heater and membrane with heater chamber fabrication used to bulk and surface micromachining technique while the planar diffuser nozzle was fabricated using mold replication technique.

\subsection{Micro heater fabrication}

Figure 4 represents the fabrication step of the microheater system. Firstly, a thick $180 \mu \mathrm{m}$ boron silica glass substrate was cleaned using RCA standard procedure to clean any grease or impurities on the glass surface. Then, the glass is baked in a hot place at $120^{\circ} \mathrm{C}$ for 20 minutes for hydrophilic treatment purposes. Next, the glass is coated with a $12 \mathrm{um}$ photoresist and pattern transfer is performed through the photolithography process. The AZ $400 \mathrm{~K}$ developer with a ratio of 1:2 was used to develop the pattern. After drying the pattern, a metal sputtering machine was used to deposit $50 \mu \mathrm{m}$ chromium as an adhesive layer and $200 \mu \mathrm{m}$ of platinum as a conductive layer on the glass substrate. Finally, the lift-off method is performed to reveal the heater conductive element structure. 


\subsection{Micro actuator fabrication}

A $680 \mu \mathrm{m}$ thick $<100>$ silicon nitride $\mathrm{Si}_{3} \mathrm{~N}_{4}$ was used for a base substrate of the thin film membrane and microchamber. After the standard RCA cleaning process was completed, AZ 4620 photoresist was spun onto both sides of the nitride surface. The photoresist on the backside of nitride is thicker than the other side due to the diaphragm requirement for the next process. Then the sample was placed on the hotplate for the pre-the baking step at approximately $3 \mathrm{~min}$ at $120^{\circ} \mathrm{C}$. Then, the process was followed by pattern transfer also known as phophotolithographyuffered oxide etch (BOE) solution was used to remove the exposed nitride while the unexposed nitride layer is used as a mask for potassium hydroxide $(\mathrm{KOH})$ etching. Next, $\mathrm{KOH}$ with the concentration of $45 \mathrm{wt} \%$ at $80^{\circ} \mathrm{C}$ was applied to remove the undesired silicon layer until 100um thick membrane was left. At this point, polyimide was deposited on the backside of the other wafer. The polyimide needs to be cured with incremental degradation temperature from $50-350^{\circ} \mathrm{C}$ for 1 hour. The sample was then reimmersed in $35 \mathrm{wt} \% \mathrm{KOH}$ solution at $70^{\circ} \mathrm{C}$ to etch the rest of the residual silicon layer. At this point, careful observation was required to avoid the membrane tearing or damage due to the very thin layer etched. The etching was stopped after the polyimide membrane layer reveal. Until here the thin microchamber was completely performed. All of these process and step is presented in Figure 5.
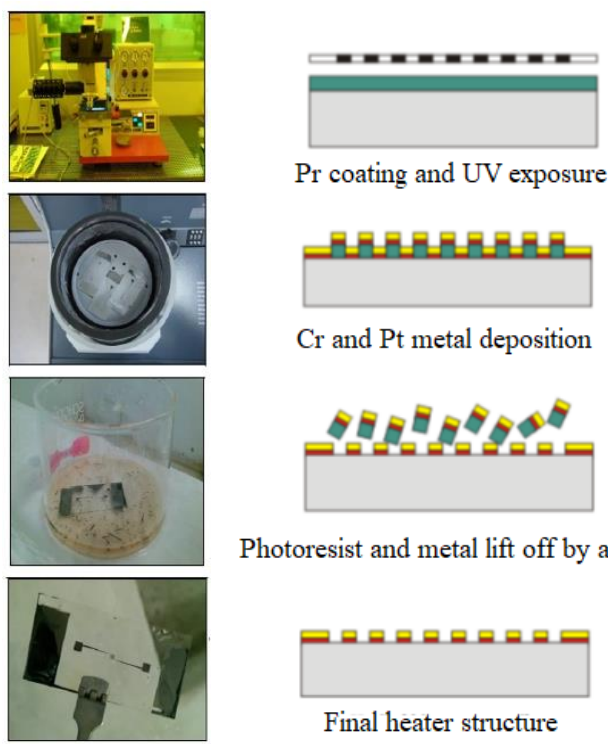

$\mathrm{Cr}$ and $\mathrm{Pt}$ metal deposition

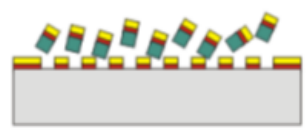

Photoresist and metal lift off by acetone

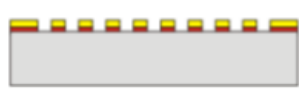

Final heater structure
Resistance

Platinum

Chromium

Substrate 
Figure 4: Fabrication steps for microheater

\subsection{Diffuser nozzle fabrication}

In order to construct a planar diffuser nozzle, the mold master structure must first be constructed. Same as the previous process, silicon dice must be cleaned using the RCA standard procedure before proceed to the next steps. SU8 2075 was then poured on the silicon substrate and spun on the spin coater at $500 \mathrm{rpm}$ followed by $2000 \mathrm{rpm}$ to get the thickness of $110 \mu \mathrm{m}$. Next, a photolithography process was performed to transfer the diffuser nozzle pattern. The process was then followed by the pre-baked and post-baked technique before the mold was revealed by the SU8 developer and Isopropanol (IPA). Finally, the hard mold master structure of the planar diffuser nozzle was obtained.

As shown in Figure 6, the PDMS mixture was then poured on into the SU8 mold master structure. Before that the $2 \mathrm{~cm}$ Tygon tube was attached to the master mold. Next, the sonification process was performed to cure the PDMS replica. The cured PDMS replicas were then peeled off from the SU8 master pattern and combined with the previous component to represent a thermopnumatic micropump system. The diffuser nozzle was fabricated with the dimension of 20 $\mathrm{mm}^{2}$ at the inlet and outlet pumping chamber, $110 \mu \mathrm{m}$ depth and 20 $\mathrm{mm}$ of total length with divergence angle id $10^{\circ}$. 

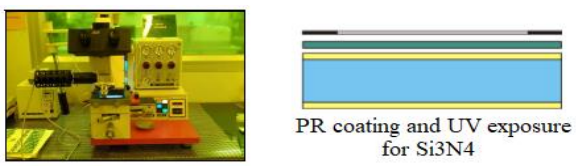

PR coating and UV exposure for Si3N4
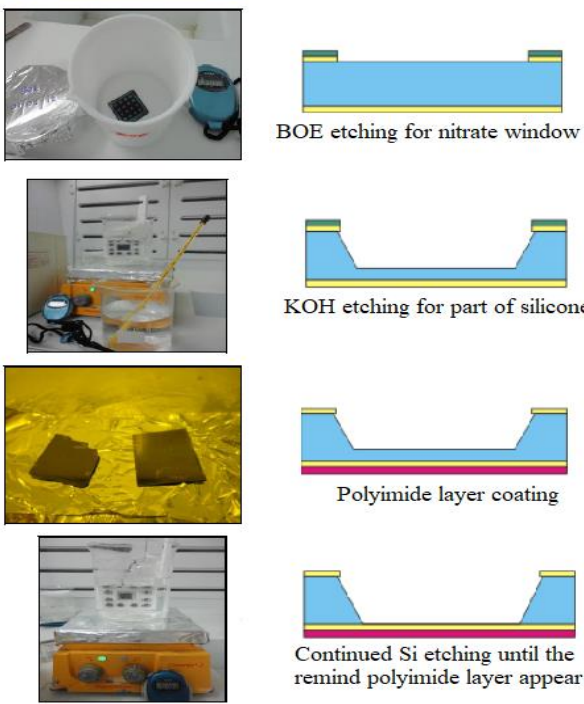

Polyimide layer coating

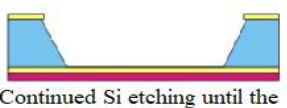

$\square$ Photoresist

$\square$ Nitrate

Continued Si etching until the $\square$ Polyimide remind polyimide layer appear $\square$ Silicone

Figure 5: Fabrication steps for the microactuator 
Overall, the thermo pneumatic micropump constructed consisted of a microheater, thin-film membrane with a heater chamber and planar diffuser nozzle. The microheater is built with platinum as a conductive heating element which is deposited onto boron silica glass surfaces using the surface micromachining technique. An adhesive agent between platinum and glass was $50 \mu \mathrm{m}$ deposited chromium. Thin membrane polyimide is constructed with silicon microchamber using bulk micromachining technique act as the microactuator while the microchannel or diffuser nozzle element was fabricated from PDMS using soft lithography or replica molding technique. The whole specification of the thermopenumatic micropump can be referred on Table 1 while the actual thermo pneumatic micropump is illustrated in Figure 7.
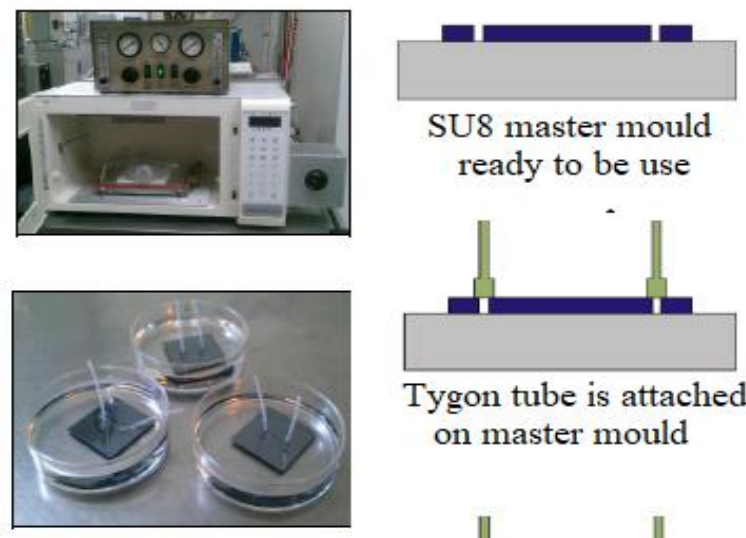

Tygon tube is attached on master mould
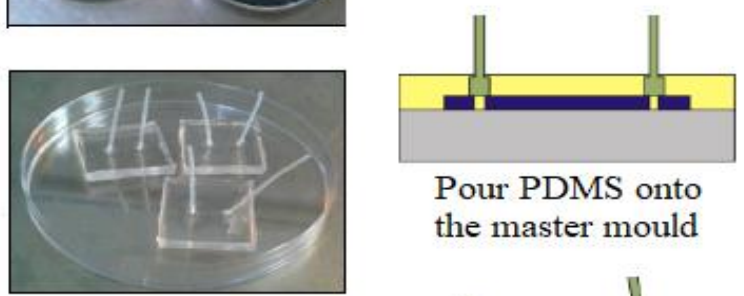

Pour PDMS onto the master mould

Tygon tube $\longrightarrow$ PDMS

SU8 master mould Silicon substrate

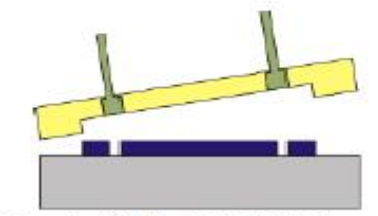

Peel off the PDMS layer

Figure 6: Fabrication steps for planar diffuser nozzle 
Table 1: Specification of thermo-pneumatic micropump

\begin{tabular}{|l|c|c|}
\hline \multicolumn{1}{|c|}{ Parameters } & Material & Unit \\
\hline Micro Heater & $\mathrm{Pt}, \mathrm{Cr}$ & \\
Width & $\mathrm{w}$ & $50 \mu \mathrm{m}$ \\
Spaces & $\mathrm{s}$ & $50 \mathrm{~nm}$ \\
Thickness (Pt, Cr) & $\mathrm{t}$ & $200,50 \mathrm{~nm}$ \\
Total length & 1 & $20 \mathrm{~mm}$ \\
\hline Thin Film Membrane & $\mathrm{Pi}$ & \\
Thickness & $\mathrm{t}$ & $4 \mu \mathrm{m}$ \\
Area & $\mathrm{A}$ & $4 \mathrm{~mm}$ \\
\hline Micro Chamber & $\mathrm{h}$ & $680 \mu \mathrm{m}$ \\
Depth & $\mathrm{A}$ & $20 \mathrm{~mm}$ \\
Window Area & pole & $54.7^{\circ}$ \\
Trench & $\mathrm{h}$ & $110 \mu \mathrm{m}$ \\
\hline Diffuser/nozzle element & 1 & $40 \mathrm{~mm}$ \\
Depth & \multicolumn{2}{|c}{} \\
Total length & \multicolumn{2}{|c|}{} \\
\hline \multicolumn{2}{|c|}{}
\end{tabular}

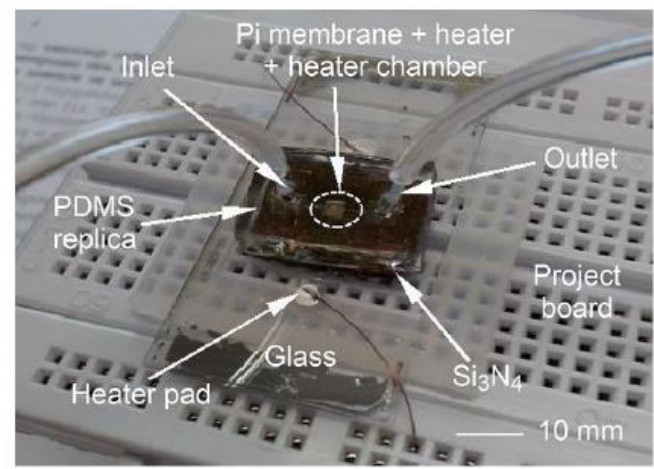

Figure 7: Actual thermopneumatic micropump

\subsection{MEASUREMENT AND TESTING}

After the measurement and functionally testing for each component is carried out, these three component is then integrated into one complete system using an anodic bonding technique and the whole system namely as thermopneumatic micropump. The functionality, performance, and capability of the micropump to pump the fluid were carried out as mentioned in the next paragraph.

\subsection{Experimental setup}

Figure 8 shows a schematic diagram and layout of a functionality test 
of a thermo pneumatic micropump in the laboratory. The actual measurement is also illustrated in Figure 9. The Aigo scope image 9.0 microscope was used to record the fluid flow rate during the test. The microscope lens was placed aligned with the measurement scale and a Tygon tube. Colored ionized water was used as the fluid in the test to provide a clear observation and analysis. Next, the power supply is connected to the microheater using a wire connection on the miniproject board and a connector pad of the microheater.

When the supply is applied to the microheater, the color liquid slowly enters the diffuser inlet into the fluid chamber and then exits again at the outlet nozzle. This meniscus movement was captured and recorded for further flow rate measurement and calculation.

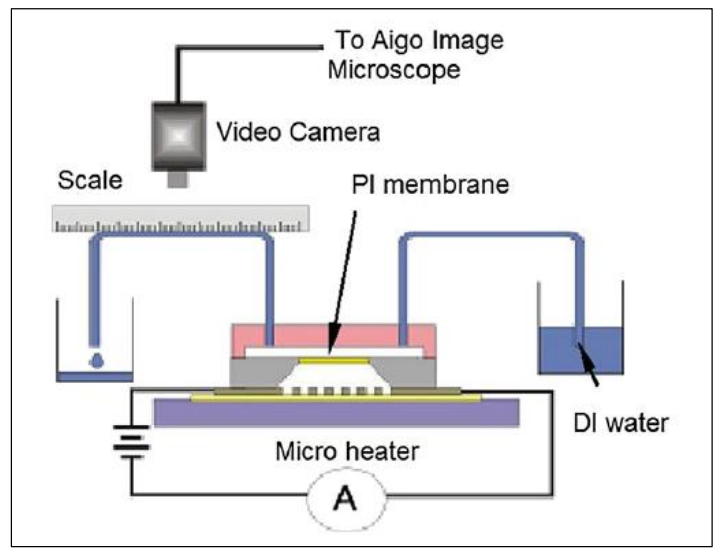

Figure 8: Schematic diagram and layout for thermo pneumatic micropump functionality test

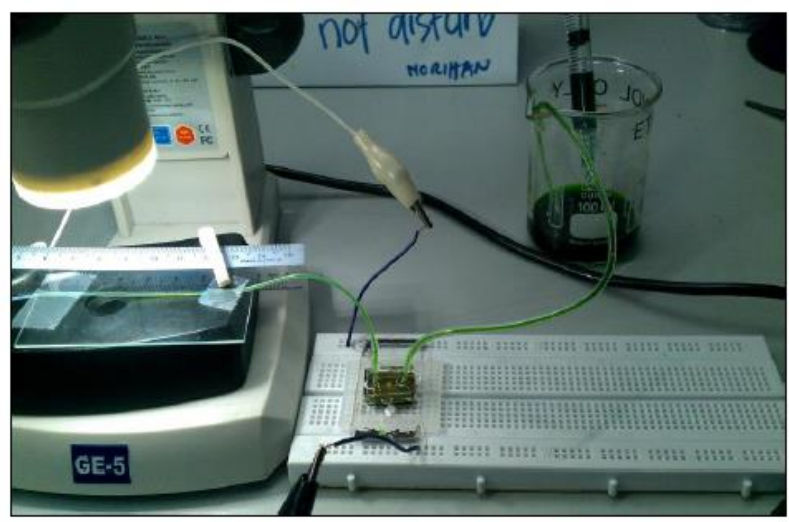

Figure 9: Actual functionality test of thermo pneumatic micropump 


\subsection{RESULTS AND DISCUSSION}

Figure 10 shows the recorded and captured movement of fluid from the experimental test. An initial scale of fluid before any movement is marked with the yellow line as well a reading scale is set in every 30 seconds with a scale size of $0.1 \mathrm{~mm}$. The flow rate produced from the fluid motion can be determined by calculating the liquid flow along the Tygon tube with volume count in the cylinder. The meniscus transition distance fluid in this figure is taken for 2 minutes 30 seconds with the maximum input voltage of $12 \mathrm{~V}$.

Finally, the result of voltage supply versus flow rated is recorded in Figure 11. As shown in this figure, the pumping rate of the micropump is $770 \mathrm{pL}$ at a $6 \mathrm{~V}$ input supply with $33.5^{\circ} \mathrm{C}$ estimation temperature in the microchamber, while the maximum flowrate is $12.5 \mathrm{~nL}, 12 \mathrm{~V}$ and $63.5^{\circ} \mathrm{C}$ respectively. According to the previous functionality test on the thin film membrane and microchamber, this is the final point where the experimental test should be terminated. If the temperature inside the chamber exceeds $70^{\circ} \mathrm{C}$, the thin film membrane will be torn and damaged which means all the micropump systems will also collapse.

From the experiment, it can be observed that when the power supplied increases, significantly the temperature inside the microheater will increase and the pumping rate also increase respectively. Based on previous findings in [19], the deflection of the corrugated diaphragm is about three times compared with the flat one. However, since the paper used the same concept of air expansion and cooling in the chamber cavity, both flowrate obtained can be used for the drug delivery system. As mentioned in [20], micro-dosing through drug delivery application devices requires an extremely small flow rate but there is no specific flow rate for each microdosing. There is various flowrate that has been done by the previous researcher which in as smaller $0.13 \mu \mathrm{L}$ as and higher as $4800 \mu \mathrm{L}$. The flow rate range depends strongly on application. As mentioned in [20], the achieved flow between $0.77 \mathrm{~nL} / \mathrm{min}$ and $12.5 \mathrm{~nL} / \mathrm{min}$ in this paper is suitable for microdosing the animal trials on small lab animals. The main concern for the drug delivery system was the safety application hence a crucial for them to have an accurate and precise flow rate. Therefore, in each design of the drug delivery system, the ability and capability of the system must be known to identify where are suitable applications can be consumed. 
The material used to fabricate the components are relatively economic, easy to obtained and fabricate. Nevertheless, the consumption of supply below $12 \mathrm{~V}$ provides a distinct advantage because it is portable and easy to obtain.
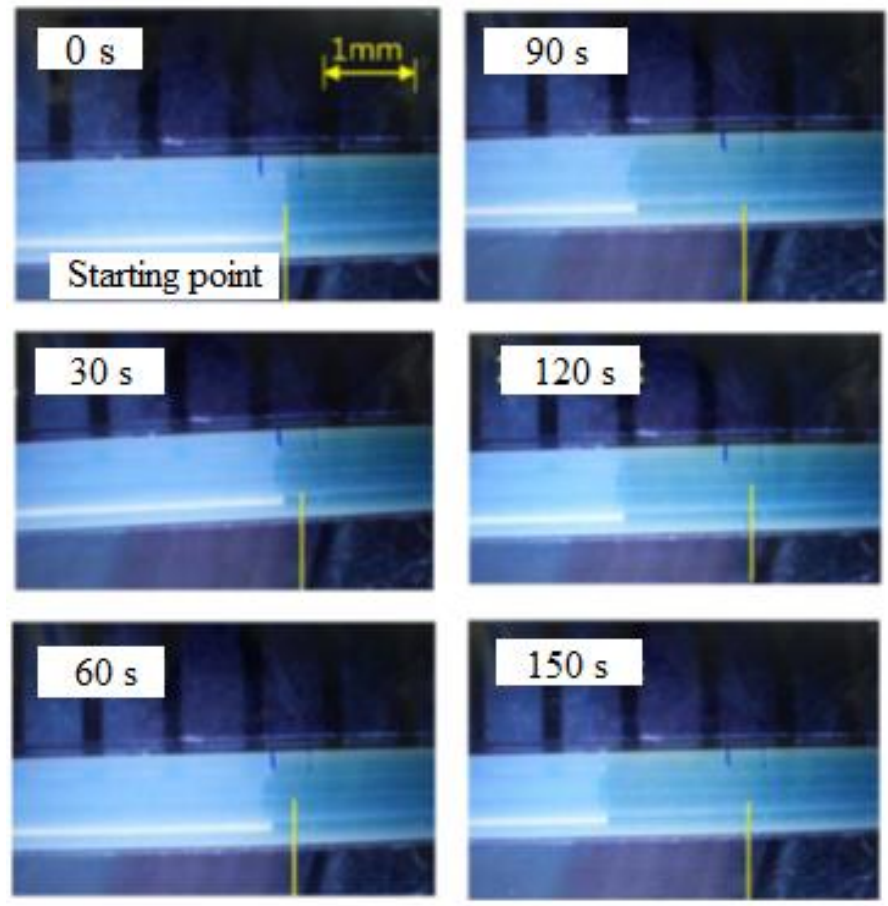

Figure 10: Distance of fluid motion for 2 min 30 second

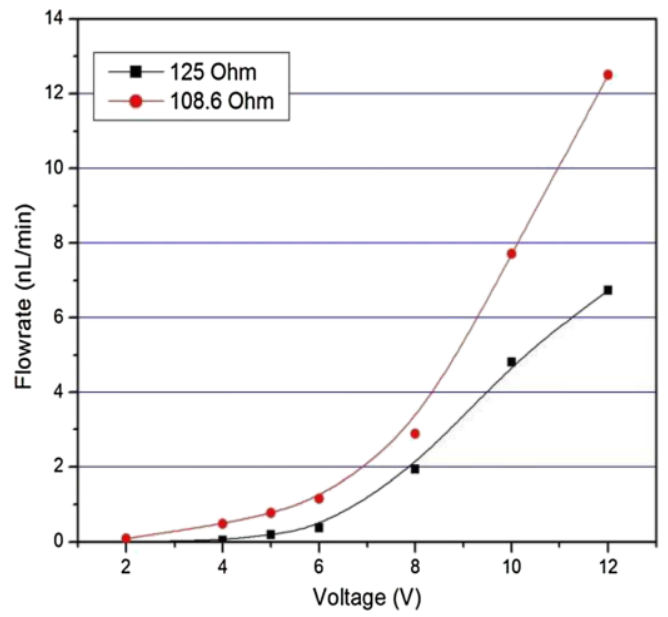


Figure 11: Relationship between flow rate and applied voltage.

\subsection{CONCLUSION}

In this paper, a thermo pneumatic micropump was successfully fabricated using three different processes and materials. Material, technique, dimension, and component used are explained in detail. The three components were then integrated using an anodic bonding technique to be complete the micropump system. Next, the functionality tests and flow rate measurement for the micropump are performed to determine the suitable application of the micropump in the medical field based on performance and medical device requirements. The experimental results show that with the pumping rate of $770 \mathrm{pL}-220 \mathrm{~nL}$, the term pneumatic system is suitable to be used as a therapeutic substances device in a drug delivery system.

\subsection{ACKNOWLEDGMENTS}

Authors would like thanks to Fakulti Kejuruteraan Elektronik and Kejuruteraan Komputer (FKEKK), Universiti Teknikal Malaysia Melaka for sponsoring the study. This researh is also support by MEMS Group in Institute of Microelectronic and Naonatechnology (IMEN), Universiti Kebangsaan Malayisa under Arus Perdana Grant UKM.

\subsection{REFERENCES}

[1] J .S. Kochhar S. Y. Chan, P. S. Ong, W. G. Lee, L. Kang, Microfluidic Devices for Biomedical Applications, Woodhead Publishing Series, 2013, pp.231-280

[2] Dennis L. Polla, Arthur G. Erdman, William P. Robbins, David T. Markus, Jorge Diaz-Diaz, Raed Rizq, Yunwoo Nam, and Hui Tao Brickner, "Microdevices in Medicine", Annual Review of Biomedical Engineering, 2000, Vol. 2, pp. 551-576

[3] B. Bhattaccharyya, "Electrochemical Micromachining for Nanofabrication, MEMS and Nanotechnology", William Andrew Publication, 2015

[4] M. W. Ashraf, S. Tayyab,N. Afzulpurkar, "Micro Electromechanical Systems (MEMS) Based Microfluidic Devices for Biomedical Applications", 2011, Int. J. Molecular Sciences, Vol. 12 (6), pp. 3648-3704.

[5] Yao-Nan Wanga, Lung-Ming Fu, Yao-Nan Wanga, Lung-Ming 
$\mathrm{Fu}$, "Micropumps and biomedical applications - A review", J. Microelectronic Eng, 2008, Vol. 195, pp. 121-138

[6] N. M. Elman and U. M. Upadhay, "Medical Applications of Implantable Drug Delivery Microdevices Based on MEMS (Micro-Electro-Mechanical-Systems)", J. of Current Pharmaceutical Biotechnoloy, 2010, Vol. 11, pp. 398-404

[7] Faranak Rajab, Alireza Bakhshi, Ghazale Kazemi, "Drug delivery applications of mechanical micropumps,", J Conference: International Conference on Applied Researches in Science \& EngineeringAt: Amsterdam, Netherlands. Jan 2021, pp. 1-18.

[8] Agnes Bußmann, Henry Leistner, Doris Zhou, Martin Wackerle 1, Yücel Congar, Martin Richter, "Piezoelectric Silicon Micropump for Drug Delivery Applications", J. Applied Sci. Vol. 11, 2021, pp1-14.

[9] Farid Amirouche, Yu Zhou \& Tom Johson "Current micropump technologies and therir biomedical application", J. Microsystem technologies, 2009, Vol.15, pp. 647-666.

[10] D. I. Brian and V. G. Surech "Recent Advances in microscale pumping technologies: a review and evaluation Microfluidic Nanofluidic", 2008, Vol. 5. pp.145-174.

[11] S. R. Hwang, W. Y. Sim, D. H. Jeon, G. Y. Kim, S. S.Yang, \& J. J. Park, (2005). "Fabrication and test of a sub microliter level thermopneumatic micropump for transdermal drug delivery", 3rd IEEE/EMBS Special Topic Conference on Microtechnology in Medicine and Biology, 2004, pp. 143-145.

[12] S. Zimmermann, J. A. F. D. Liepmann \& A. P. Pismo, “A Planar Micropump Utilizing Thermopneumatic Actuation and In-plane Flap Valves", 17th IEEE International Conference on Micro Electro Mechanical Systems (MEMS), Sep 2004, pp. 462-465.

[13] Manoj Pandey and P.C. Upadhyay, (2012), "Design and Simulation of Valve Less PZT Micropump for Drug Delivery System". Int. Journal of Advancement Technology, Vol. 3, Issue 2 pp. $92-100$

[14] Stemme, G., \& Stemme, E. (1993). A valveless diffuser with no nozzle-based pump. Sensor and Actuators A, 2(39), pp. 156-167

[15] A. E. Guber, M. Heckele, D., Herrmann, A., Muslija, V. Saile, L. Eichhorn,G., Knebel. (2004). Microfluidic lab-on-a-chip systems 
based on polymers - fabrication and application. Chemical Engineering Journal, 2004, Vo. 101, pp .447-453.

[16] Iverson, B. D., \& Garimella, S. V. (2008). Recent Advances in Microscale Pumping Technologies: A Review and Evaluation and evaluation. Microfluidics and Nanofluidics, Vol. 5, pp. 145-174.

[17] Nguyen, N.-T., \& Truong, T.-Q. (2004). A fully polymeric micropump based on laminar technology. Journal of Micromechanics and Microengineering. Vol. 14, Issue 4, pp. 632-638.

[18] Dau, V. T., Dinh, T. X., Tanaka, K., \& Sugiyama, S. (2009). Study on the geometry of valveless-micropump. 2009 IEEE/ASME International Conference on Advanced Intelligent Mechatronics, pp. 308-313.

[19] Jeong, O. C., \& Yang, S. S. (2000). Fabrication and test of a thermopneumatic micropump with a corrugated $\mathrm{p}+$ diaphragm. Sensors and Actuators A: Physical, 83(1-3), pp.249-255.

[20] Agnes B. B, Lorenz M. G, Claudia P. D, Thomas A. T, Axel W, Martin Richtera. (2021) "Microdosing for drug delivery application-A review", Sensor and Actuators A, , Vol. 330, pp. $1-26$ 